\title{
An Investigation of Hot Deformation Response of Particulate-Reinforced Magnesium $+4.5 \%$ Titanium Composite
}

\author{
B. K. Raghunath ${ }^{\mathrm{a}}$ R. Karthikeyan ${ }^{\mathrm{a} *}$, M. Gupta ${ }^{\mathrm{b}}$ \\ a'Department of Manufacturing Engineering, Annamalai University, Annamalai Nagar, \\ Chidambaram, Tamilnadu, 608002, India \\ ${ }^{b}$ Department of Mechanical Engineering, National University of Singapore, \\ 10 Kent Ridge Crescent, Singapore, 119260, Singapore
}

Received: September 22, 2005; Revised: March 31, 2006

\begin{abstract}
The deformation response of magnesium based metal matrix composite was investigated by means of hot compression tests. The flow curves were obtained in the temperature and strain rate range of $300-500{ }^{\circ} \mathrm{C}$ and 0.001-1 $\mathrm{s}^{-1}$ respectively in order to obtain the processing maps of the studied material and interpreting them on the basis of the dynamic material model. Micro-structural characterization studies conducted on the deformed composite samples, using optical and scanning electron microscopy, revealed a recrystallized grain morphology, debonding of Titanium particles, particle breakage and cracking of the matrix. The observations were performed in order to describe the behavior of the material under hot forming operation in terms of material damage and micro- structural modification.
\end{abstract}

Keyword: magnesium composite, disintegrated melt deposition, processing maps, hot workability

\section{Introduction}

The development of metal matrix composites (MMCs) has been one of the major innovations in materials engineering. Metal matrix composites provide an opportunity to combine the metallic properties of matrices with the ceramic properties of the reinforcing phases leading to a composite material with greater modulus, strength, wear resistance, and thermal stability. These materials are attractive for advanced structural, aerospace, automotive, and industrial applications ${ }^{1}$.

Hot formability studies have revealed the deformation behavior of the discontinuously reinforced magnesium matrix composites are more sensitive to processing variables such as temperature and strain rate than the unreinforced alloys. This is due to the presence of hard particles in the soft matrix, which causes plastic flow localization at the particle-matrix interfaces ${ }^{2}$. Moreover, grain boundary sliding occurring at the high temperatures above $470{ }^{\circ} \mathrm{C}$ and low strain rates below $0.001 \mathrm{~s}^{-1}$ can lead to the formation of wedge-shaped cracks at grain boundaries that are initiation sites for damage and affect the mechanical properties of the component. Thus a proper selection of the forming conditions is necessary to produce sound components ${ }^{3}$.

Besides hot working simulations through either hot compression or torsion tests, necessary to obtain the constitutive parameters for numerical analysis, an alternative approach to the definition of optimum hot-working conditions is offered by processing maps. A 'processing map' is the super-imposition of a 'power-dissipation map' with an instability parameter on a process variable space of $1 \mathrm{~s}^{-1}$ and $500{ }^{\circ} \mathrm{C}$.

In the plastic forming process the Dynamic Material Model ${ }^{4}$ considers the work piece as a dissipator of the power supplied by a particular source. The total power dissipated $\mathrm{P}$ is calculated to be:

$$
P=\sigma \dot{\varepsilon}=\int_{0}^{\dot{\varepsilon}} \sigma d \dot{\varepsilon}+\int_{0}^{\sigma} \dot{\varepsilon} d \sigma
$$

where $\sigma$ is the instantaneous flow stress that is the material's response to the applied strain rate $(\dot{\varepsilon})$ to reach a given strain $\varepsilon$. The first integral defined as $\mathrm{G}$ content represents the main power input dissipated in the form of a temperature rise. The second integral, defined as J co- content, represents the power dissipated by metallurgical processes such as recovery, recrystallisation and phase transformation, and the harmful effects cavity formation and particle damage. The efficiency of power dissipation $(\eta)$ represents the relative rate of internal entropy production during hot deformation and characterizes the dissipative microstructures under different temperature and strain rate conditions is directly calculated by interpolating the data obtained from the mechanical tests. This parameter was used to instruct power-dissipation maps ${ }^{5}$ which permits an identification of the region of optimum workability, defined as the region of high power dissipation. However, since the damage mechanisms such as wedge cracking, correspond to high values of power dissipation efficiency, the results obtained by analyzing the maps require a detailed microstructural investigation to be validated.

A further point has been the introduction of instability maps ${ }^{6}$. Which defines metallurgical instability during plastic flow these are based on the principles of irreversible thermodynamics of large plastic flow, which considers the variation in entropy produced by the change in strain. The instability criteria formulated on this basis defines the temperature versus strain rate maps which identifies the regions of unstable flow. Typical manifestations of unstable flow are a) adiabatic shear bands, b) localized shear, c) Luders bands, etc.

The use of power dissipation efficiency and instability maps ${ }^{7}$ is a promising method to predict the optimum processing conditions and these have been used to analyze the deformation response of several metal-matrix composites. The aim of this paper is to investigate the hot workability of a magnesium matrix composite reinforced with $4.5 \% \mathrm{Ti}$ particles. In particular, hot compression tests were used to obtain processing maps. These were constructed taking into account the largely accepted conclusions on the form of the constitutive equation that correlates flow stress, strain rate and temperature in these materials. A microstructural investigation of particle behavior was carried out in the tested sample for the purpose of correlating the flow instability region with micro-structural features. 


\section{Experimental Procedures}

The Mg-Ti composites were processed and manufactured by using the disintegrated melt deposition technique, which is briefly explained by Gupta et al. ${ }^{1}$. The composite was extruded and provided by National University of Singapore.

Isothermal hot compression tests were conducted using FIE servo controlled universal testing machine with a maximum load capacity of $100 \mathrm{KN}$.

The hot deformation of the composite material was investigated by hot compression tests at temperatures of $300-500{ }^{\circ} \mathrm{C}$ and in the strain rate range $0.001-1 \mathrm{~s}^{-1}$. The flow stress curves were obtained by using the classical equations for hot compression tests ${ }^{8}$. Light microscopy (LM) was used to evaluate micro-structural evolution in terms of grain size and shape behavior for all the hot forming conditions. Scanning electron microscopy observations were performed in order to evaluate damage to the material in terms of (a) particle fracture and (b) decohesion between the matrix and the particle. Specimens deformed in compression were sectioned parallel to the compression axis and the cut surface was prepared for metallographic examination using standard techniques. The specimens were etched using $\mathrm{Nital}+$ Methanol reagent and light micrographs taken using polarized light. A resistance heating split furnace having $\mathrm{SiC}$ heating elements was used to surround the platens and specimen. The specimens were coated with a borosilicate glass paste which acted both as a lubricant and as a protective coating. The testing temperatures ranged from $300-500{ }^{\circ} \mathrm{C}$ in intervals of $50{ }^{\circ} \mathrm{C}$ and at constant true strain rates of $0.001,0.01,0.1$, and $1 \mathrm{~s}^{-1}$. The specimens were deformed to half the height in each case to impose a true strain of about 0.5 .

\section{Results and Discussion}

The load-stroke data obtained in compression were processed to obtain true stress-true plastic strain curves using the standard equations 9 . The flow stress data obtained at the different temperatures, strain rates, and strains were corrected for adiabatic temperature rise, by linear interpolation between $\ln \sigma$ and $1 / T$, where $\sigma$ is the flow stress and $\mathrm{T}$ the test temperature (Table 1). A cubic spline fit between $\ln \sigma$ and $\ln \dot{\varepsilon}$, was used to obtain the flow stress at smaller temperatures and strain rate intervals and strain rates sensitivity $\mathrm{m}$ using the constitutive equation

$$
\sigma=K \dot{\varepsilon}^{m}
$$

where $\dot{\varepsilon}$ is the strain rate, and $\mathrm{K}$ is a constant. As described by Prasad et al. ${ }^{9}$, two dimensional power dissipation maps at different strains were generated by plotting the efficiency of power dissipation $(\eta)$. Where $\eta$ is given by

$$
\eta=\frac{2 \mathrm{~m}}{\mathrm{~m}+1}
$$

Regimes of flow instabilities were established using the continuum instability criterion given by

$$
\xi(\dot{\varepsilon})=\frac{\partial \ln (\mathrm{m} / \mathrm{m}+1)}{\partial \ln \varepsilon}+\mathrm{m}<0
$$

In this inequality, the left hand side represents the dimensionless instability parameter $\xi(\dot{\varepsilon})$, a negative value of which indicates unstable flow behavior.

\subsection{Flow curves}

The shape of stress-strain curves is considered to contain some information related to the mechanisms of hot deformation ${ }^{10}$. For example, flow-softening type of stress-strain behavior with an initial peak stress oscillation is taken to suggest dynamic recrystallisation (DRX). However, similar behavior can also be due to flow instability.

\begin{tabular}{|c|c|c|c|c|c|c|}
\hline \multirow[t]{2}{*}{ Strain rate $\mathrm{s}^{-1}$} & \multirow[t]{2}{*}{ Strain } & \multicolumn{5}{|c|}{$\begin{array}{l}\text { Flow stress (in MPa) of different } \\
\text { temperature }\end{array}$} \\
\hline & & $300^{\circ} \mathrm{C}$ & $350{ }^{\circ} \mathrm{C}$ & $400{ }^{\circ} \mathrm{C}$ & $450{ }^{\circ} \mathrm{C}$ & $500^{\circ} \mathrm{C}$ \\
\hline \multirow[t]{5}{*}{0.001} & 0.1 & 70 & 57.4 & 34.3 & 23.8 & 11.2 \\
\hline & 0.2 & 53.9 & 56.7 & 28 & 19.6 & 11.2 \\
\hline & 0.3 & 67.2 & 59.5 & 32.9 & 22.4 & 11.2 \\
\hline & 0.4 & 67.9 & 59.5 & 35 & 23.1 & 11.2 \\
\hline & 0.5 & 68.5 & 56 & 34 & 23 & 11.2 \\
\hline \multirow[t]{5}{*}{0.01} & 0.1 & 82.6 & 65.8 & 44.1 & 31.5 & 23.8 \\
\hline & 0.2 & 80.5 & 60.9 & 39.2 & 30.1 & 21.7 \\
\hline & 0.3 & 88.2 & 72.1 & 43.4 & 32.9 & 24.5 \\
\hline & 0.4 & 82.6 & 68.6 & 44.1 & 32.9 & 25.2 \\
\hline & 0.5 & 80.8 & 68 & 43.8 & 35.3 & 26.1 \\
\hline \multirow[t]{5}{*}{0.1} & 0.1 & 120.4 & 98.7 & 61.6 & 46.9 & 32.9 \\
\hline & 0.2 & 102.2 & 88.9 & 62.3 & 46.2 & 27.3 \\
\hline & 0.3 & 121.8 & 100.1 & 71.4 & 51.1 & 30.8 \\
\hline & 0.4 & 123.2 & 107.1 & 67.2 & 49 & 32.2 \\
\hline & 0.5 & 122.2 & 103 & 61 & 44 & 34.3 \\
\hline \multirow[t]{5}{*}{1} & 0.1 & 144.2 & 114.8 & 94.5 & 74.13 & 48.3 \\
\hline & 0.2 & 138.6 & 121.1 & 94.5 & 72.8 & 44.1 \\
\hline & 0.3 & 152.6 & 121.1 & 107.8 & 82.6 & 51.8 \\
\hline & 0.4 & 151.2 & 122.2 & 103.6 & 79.8 & 50.4 \\
\hline & 0.5 & 143.5 & 121.8 & 101.7 & 77.6 & 52.8 \\
\hline
\end{tabular}

Table 1. Flow stress values for $\mathrm{Mg}+4.5 \% \mathrm{Ti}$ composite at various strains, strain rate and temperatures.

Likewise, DRX can occur in cases where the behavior is steady state ${ }^{11}$. The occurrence of the flow softening by the mechanism of dynamic recovery is reported to be predominant, although there is also some evidence of dynamic recrystalization (DRX). At sufficiently high temperature, DRX is initiated at some critical stress $\left(\sigma_{c}\right)$ attained at critical strain $\left(\varepsilon_{c}\right)$.

As a flow-softening phenomenon, DRX leads to a decrease in flow stress with increasing strain. It does not occur immediately after the critical stress has been attained. Beyond this critical point, the stress continues to increase until the softening due to the progress of DRX balances the continuing strain hardening in the uncrystallized parts of the material. This balance is manifested by the peak stress $\left(\sigma_{p}\right)$ attained at the strain $\left(\varepsilon_{p}\right)^{12}$. The major experimental difficulty in detecting the onset of DRX is that attainment of the critical stress does not reveal itself in the flow curve. Although the flow stress peaks in constant strain rate deformation are good indications that DRX is well underway; they do not provide information about the onset of DRX.

The flow curves obtained for $\mathrm{Mg}$ composite deformed in compression at $400{ }^{\circ} \mathrm{C}$ at different strain rates ranging from $0.001 \mathrm{~s}^{-1}$ to $1.0 \mathrm{~s}^{-1}$ are presented in Figure 1a. At higher strain rates of $1.0 \mathrm{~s}^{-1}$ with increasing strain, the flow curve exhibits an initial rapid increase to a peak value of $100 \mathrm{MPa}$ and reaches a steady state independent of further strain. This behavior of the flow curve is an indication of DRX or flow instability. This can be confirmed by material modeling and micro-structural observations. The flow stress increased with an increase in strain rate. The flow stress is significantly low \& reaches a value of $34 \mathrm{MPa}$ at lower strain rate $0.001 \mathrm{~s}^{-1}$ where as the work hardening is relatively high. Hence, the flow stress is found to increase with increase in strain. At the lower strain rates, the deformation is isothermal but at high strain rates it is adiabatic ${ }^{12}$. The steady state 


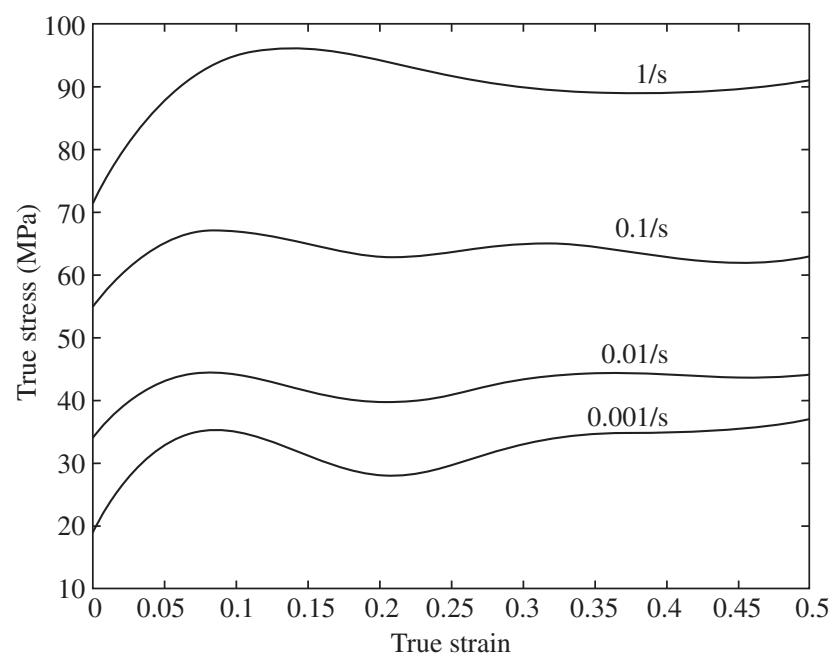

(a)

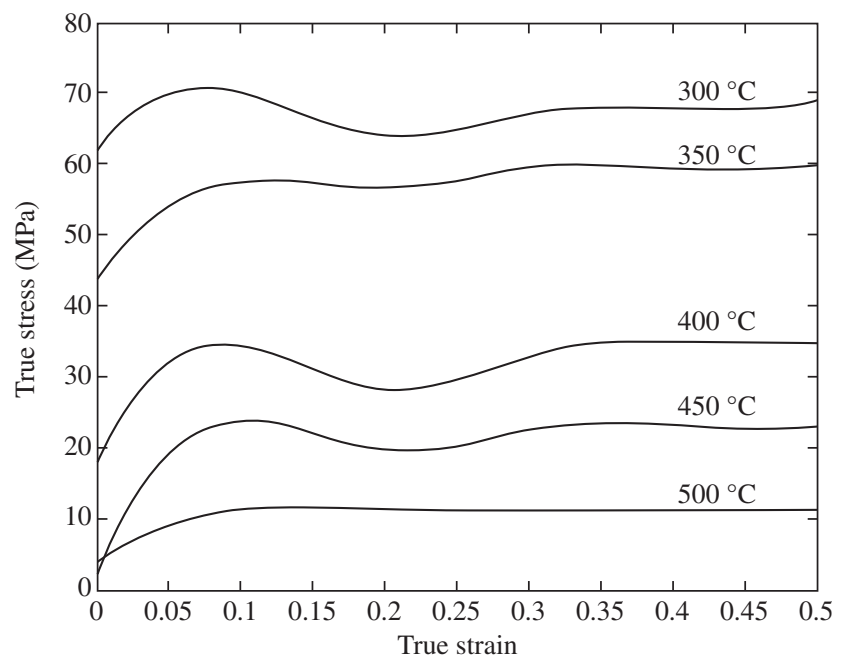

(b)

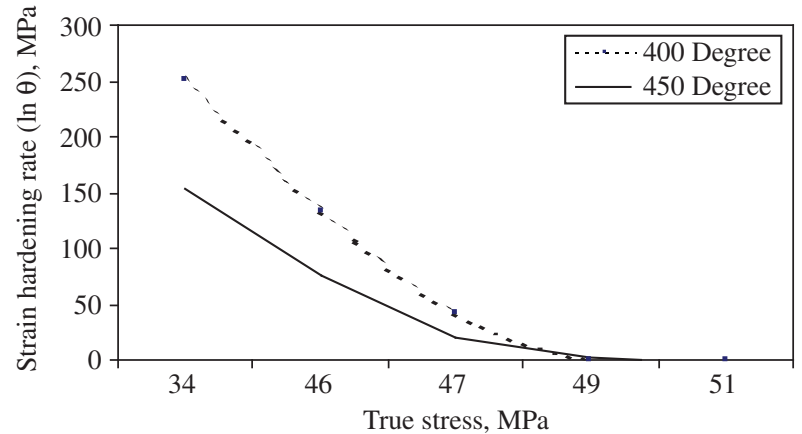

(c)

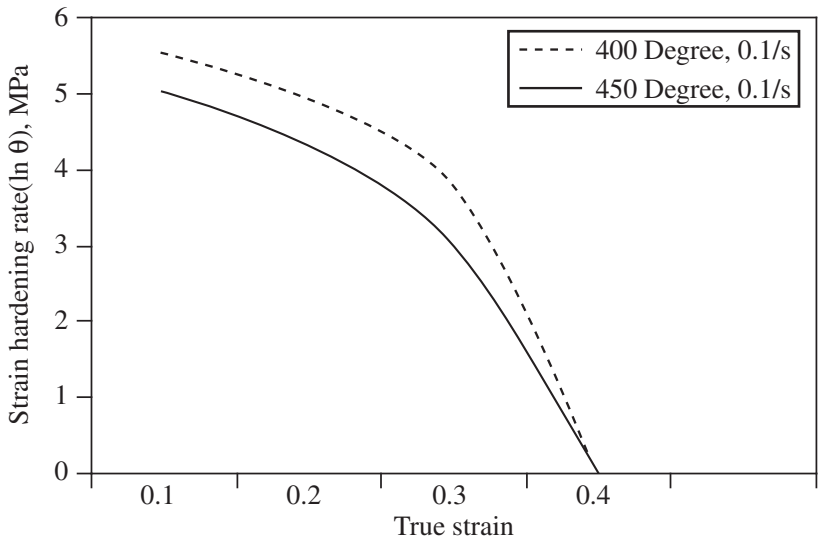

(d)

Figure 1. Flow curves of Mg composite for different: a) Strain rates at a constant temperature of $400{ }^{\circ} \mathrm{C}$; and b) Temperature and at constant strain rates $0.001 \mathrm{~s}^{-1}$. Strain hardening rate plots for $\mathrm{Mg} / 4.5 \% \mathrm{Ti}$ composites, effect of temperature on: c) Strain hardening rate; and d) critical strain at the onset of DRX.

flow curve at the lower strain rate and temperature represents dynamic recovery. Dynamic recrystallization is associated with single peak or multi peak flow curves at comparatively higher strain rates and temperature ${ }^{13}$.

The true stress-true strain at the different temperatures and at $0.001 \mathrm{~s}^{-1}$ strain rate is shown in Figure $1 \mathrm{~b}$. The true stress increases to a peak value of $70 \mathrm{MPa}$ and then falls to a value of $62 \mathrm{MPa}$ (11\% reduction) suggesting flow softening has occurred at $300{ }^{\circ} \mathrm{C}$. The flow stress decreased with an increase in temperature suggesting flow hardening is more pronounced at the lower temperature. This flow hardening is due to the combined effect of dislocation and grain growth reported by Xia et al. ${ }^{14}$ and Veh et al. ${ }^{8}$.

Ryan and McQueen observed that the presence of a stress peak in a constant strain rate flow curve leads to an inflection in the stress dependence of the strain hardening rate, is given by: $\theta=(\partial \sigma / \partial \varepsilon)$. On the basis of considerations of irreversible thermodynamics, the inflections in $(\theta-\sigma)$ plots of $\mathrm{Mg} / \mathrm{Ti}$ composite were shown in Figure1c. The strain hardening rate decreases as temperature increases, the critical stress is $49 \mathrm{MPa}$ and $46 \mathrm{MPa}$ at $400{ }^{\circ} \mathrm{C}$ and $450{ }^{\circ} \mathrm{C}$ respectively. It serves as an indication for DRX in the corresponding hot working conditions.

The ln $\theta-\varepsilon$ plot should also exhibit an inflection at the onset of DRX are shown in Figure $1 \mathrm{~d}$ critical strain is 0.2 and 0.3 at $450{ }^{\circ} \mathrm{C}$ and $400{ }^{\circ} \mathrm{C}$ respectively. Hence, DRX is initiated at $49 \mathrm{MPa}$ and attained at 0.3 , which is known as critical stress and critical strain.

\subsection{Interpretation of processing maps}

Several atomistic mechanisms that cause micro-structural damage during hot working are modeled by Raj with the aim of calculating the limiting conditions of temperature and strain rate for their occurrence. The processing maps can be interpreted on the basis of the broad principle of atomistic mechanisms represented in Raj maps ${ }^{15}$. According to the Raj maps, ductile fracture due to void formation occurs at the higher strain rates and lower temperature while wedge cracking at grain boundary triple junctions dominates at the lower strain rates and higher temperatures. The area bounded by the limiting conditions for 
these two damage processes is termed as being safe for hot working. The upper strain rate limit for this regime is set by the formation of adiabatic shear bands. In the safe regime, two processes namely a) dynamic recovery occurs at lower strain rates and temperatures and b) dynamic recrystallisation occurs at higher temperatures and strain rates. The different domains exhibited by the power dissipation maps can be identified on the basis of the corresponding efficiency variations of micro-structural features ${ }^{16}$.

The power dissipation map obtained at a strain of 0.3 is shown in Figure 2, which is an iso-efficiency contour map exhibiting the variation of efficiency of power dissipation as a function of strain rate and temperature. The processing map exhibits the following features.

1. A domain occurring in the temperature range $350-450{ }^{\circ} \mathrm{C}$ and in the strain rage range $0.01-0.1 \mathrm{~s}^{-1}$ with a peak efficiency of $34 \%$ at $430{ }^{\circ} \mathrm{C}$ and at $0.01 \mathrm{~s}^{-1}$;

2. A change in curvature of the contours occurring at $300-450{ }^{\circ} \mathrm{C}$ and in the strain rate range $0.001-0.01 \mathrm{~s}^{-1}$ and similar type of contour found at strain rate range 0.1 to $1 \mathrm{~s}^{-1}$; and

3. The instability map was developed based on the continuum criterion gives by Equation 4 the regions of map where $\xi(\dot{\varepsilon})$ is negative represents unstable flow. The variation of instability parameter $\xi(\dot{\varepsilon})$ as a function of temperature and strain rate at a strain of 0.3 shows a negative value at $300-420{ }^{\circ} \mathrm{C}$ and in the strain rate range $0.1-1 \mathrm{~s}^{-1}$ specified as shaded region in the map.

\section{Micro Structural Behavior}

The flow stress behavior of the metal-matrix composites is governed by two main processes: a) the transfer of load from the ductile matrix to the hard particles; and b) the micro-structural transformations such as recrystallization or damage phenomena. In this case the material presents decohesion at the matrix-particles interfaces or particle cracking. When the material is able to dissipate the provided power either through load transfer or metallurgical transformation, it does not reach a level high of damage ${ }^{16-18}$.

According to Srivatsan et al. ${ }^{19}$, damage induced by crucial straining of the MMCs can be described to the conjoint influences of (1) Damage associated with the discontinuous reinforcements, such as separation of the reinforcing from the matrix (2) lattice damage

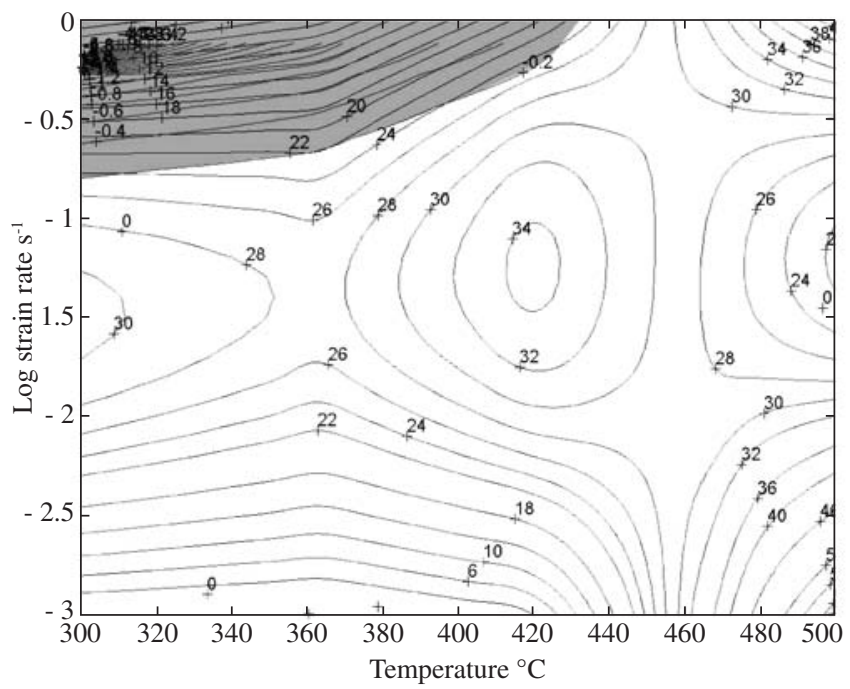

Figure 2. Power efficiency and dissipation map calculated at strain value of $\varepsilon=0.3$ : the shaded area represents the zone of unstable flow predicted by Equation 4. such as dislocation and point defects in conjunction with residual stress effects.

Gourdet and Montheillet ${ }^{20}$ stated that light metal alloys exhibit very high rates of dynamic recovery, which is generally expected to completely inhibit dynamic recrystallization. However, the formation of new grains during hot deformation of the light metal alloy has been frequently reported. Three types of dynamic recrystallization are likely to produce such a microstructure i) discontinuous dynamic recrystallization (DDRX), i.e. the classical recrystallization, which operates by nucleation and grain growth; ii) continuous dynamic recrystallization (CDRX), which involves the transformation of low angle boundaries into high angle boundaries; and iii) geometric dynamic recrystallization (GDRX), generated by the fragmentation of the initial grains. Discontinuous dynamic recrystallization, which is commonly observed in low stacking fault energy metals, remains exceptional in light metal alloys.

Sivakesava and Prasad $^{21}$ stated that Mg-Li-Al alloy does not exhibit dynamic recrystallization (DRX) even in a wide temperature-strain rate range. This may be due to the high rate of diffusion, which will not permit the formation of DRX nuclei because of an annihilation of dislocations by faster recovery processes. However, Cho et al. ${ }^{22}$ who worked on $\mathrm{Al}, \mathrm{Mg}$ alloys have observed DRX and concluded that the DRX grain size increases with a decrease in the Zener - Hollomon parameter, i.e., at the high temperature and low strain rate.

Figure 3 shows microstructure of as-cast magnesium composite, in which Ti particles are distributed through the Mg Matrix. Microstructure analysis shows a recrystallized structure at $400{ }^{\circ} \mathrm{C}$ and $0.1 \mathrm{~s}^{-1}$ in Figure 4. This is the result of nucleation and grain growth, where grains are formed around the reinforcing particle, the DRX microstructure revealed dynamically recrystallized grains. The grain boundaries were irregular and wavy in nature. Hence, this domain represents the DRX process.

Similar Dynamic recrystallization was also observed at $450{ }^{\circ} \mathrm{C}$ at a strain rate of $0.1 \mathrm{~s}^{-1}$ which is shown in Figure 5. DRX has been considered in terms of a) rate of interface nucleation and b) the rate interface growth. Rate of interface formation depends on the rate of dislocation generation and the probability of their recovery, resulting in the formation of sub-grains which on continued deformation, forms a large angle grain boundary that can migrate. The formation of a interface is enhanced due to the high rate of generation of dislo-

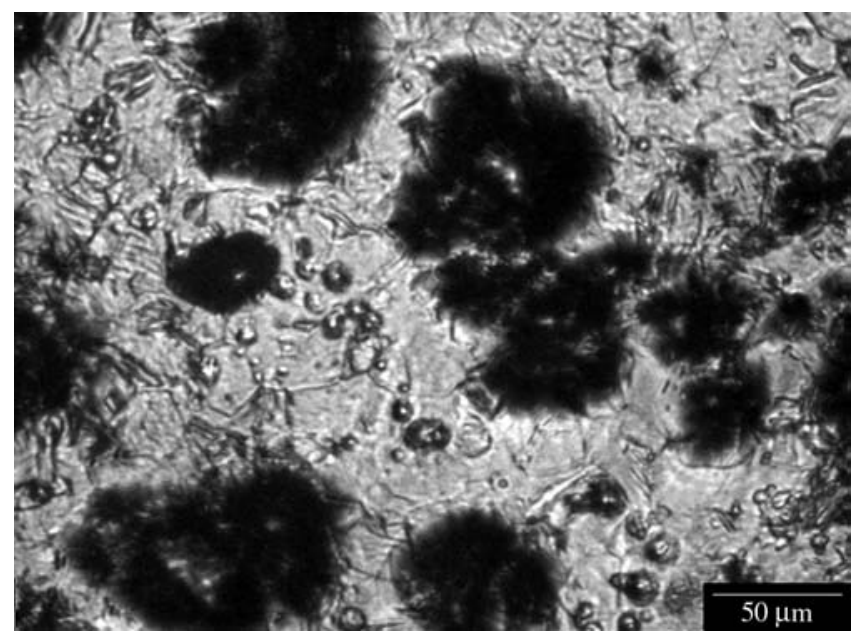

Figure 3. Microstructure of as-cast $\mathrm{Mg}+\mathrm{Ti}$ composite 


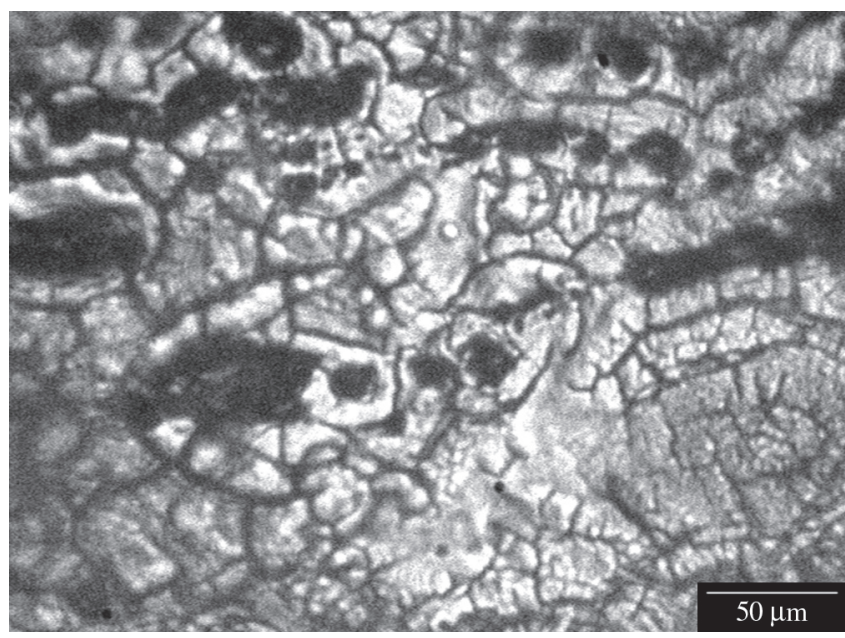

Figure 4. Microstructure in the DRX domain of $0.1 \mathrm{~s}^{-1}$ and at $400{ }^{\circ} \mathrm{C}$.

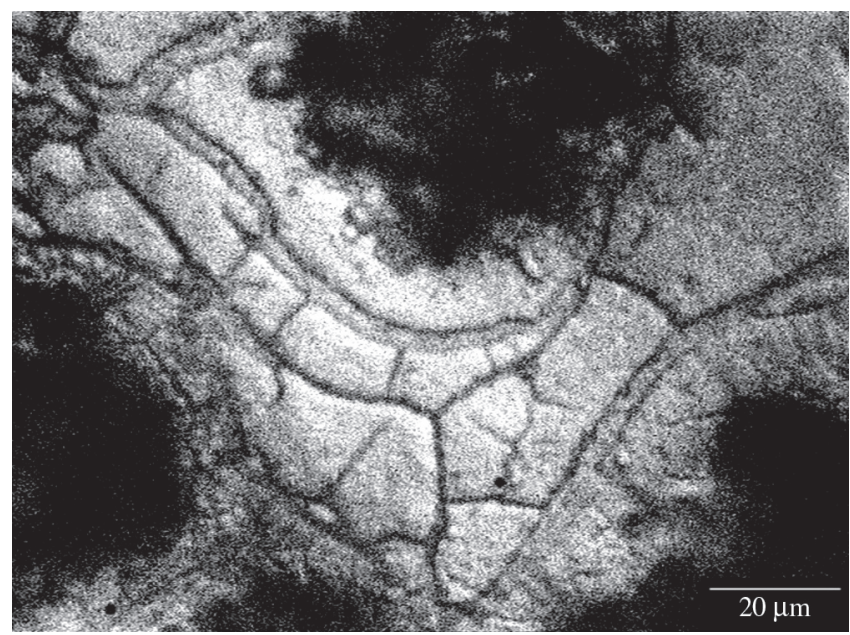

Figure 5. Microstructure in the DRX domain of $0.1 \mathrm{~s}^{-1}$ and at $450{ }^{\circ} \mathrm{C}$.

cations caused by the hard particles. This causes the formation and presences of fine substructures.

During testing of $\mathrm{Mg}+4.5 \% \mathrm{Ti}$ at $400{ }^{\circ} \mathrm{C}$ and $1.0 \mathrm{~s}^{-1}$ it is evident the particle debonding is due to interfacial failure. Magnesium matrix is seen sticking to the surface of the particle. A gap between the matrix and the particle is also seen. This implies that the bonding between the particles and the matrix is weak which is shown in Figure 6. It is observed that at $300{ }^{\circ} \mathrm{C}$ and $1.0 \mathrm{~s}^{-1}$, the $\mathrm{Mg}+4.5 \%$ Ti revealed fractured Ti particles, which has microscopic cracks in it. These cracks might lead to the fracture of the titanium particle. This is shown in Figure 7. At the lower temperature $300{ }^{\circ} \mathrm{C}$ and at high strain rate $1.0 \mathrm{~s}^{-1}$ the particles lead to greater stress concentration and breakage.

\section{Conclusions}

The hot deformation characteristics of Magnesium $+4.5 \% \mathrm{Ti}$ composite have been studied in the temperature range $300-500{ }^{\circ} \mathrm{C}$, and in the strain rate range $0.001-1 \mathrm{~s}^{-1}$ using processing maps. The following conclusions are drawn from this investigation:

1. The composite exhibits Dynamic recrystallization at $400{ }^{\circ} \mathrm{C}$ and $0.1 \mathrm{~s}^{-1}$ which are the optimum condition for hot working of the material;

2. The behavior of flow curve at $400{ }^{\circ} \mathrm{C}$ and at $0.1 \mathrm{~s}^{-1}$ with single peak curve indicates Zone of Dynamic recrystallization;

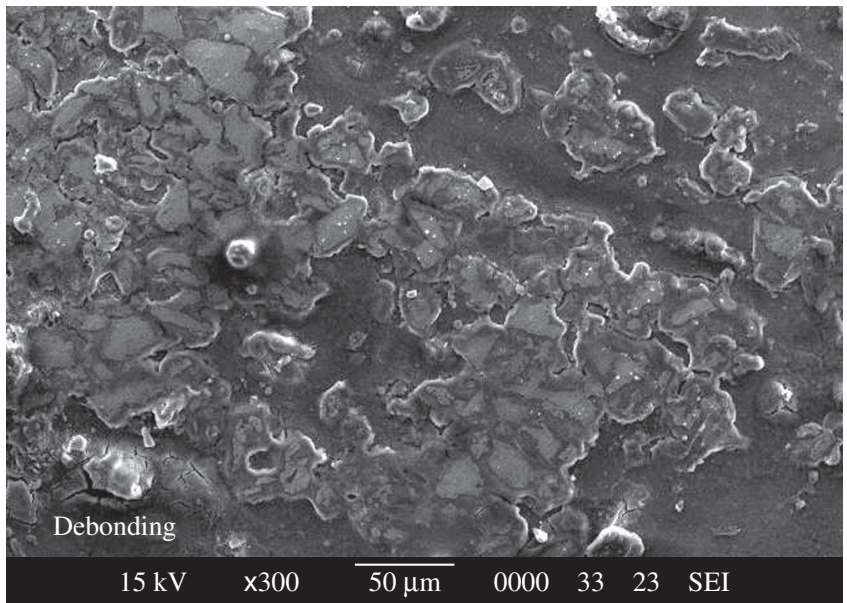

Figure 6. SEM image of debonded particle observed at $400{ }^{\circ} \mathrm{C}, 1.0 \mathrm{~s}^{-1}$.

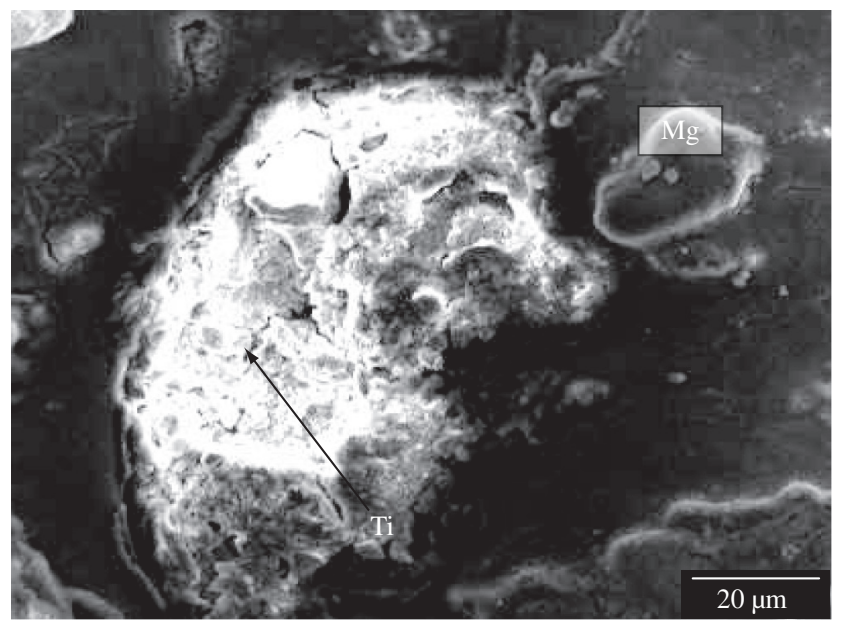

Figure 7. SEM image of particle breakage observed at $300{ }^{\circ} \mathrm{C}, 1.0 \mathrm{~s}^{-1}$.

3. Processing Map indicates DRX zone in the temperature range $360-450{ }^{\circ} \mathrm{C}$ and at strain rate $0.01-0.1 \mathrm{~s}^{-1}$ and instability zone in the temperature range $300-420{ }^{\circ} \mathrm{C}$ and at strain rate 0.1 $1 \mathrm{~s}^{-1}$; and

4. At temperature range of $300{ }^{\circ} \mathrm{C}$ to $420{ }^{\circ} \mathrm{C}$ and at strain rate 0.1 to $1 \mathrm{~s}^{-1}$ the material exhibits flow instability manifesting as particle debonding, matrix cracking and particle cracking.

\section{Acknowledgment}

The authors from Annamalai University are grateful to All India Council For Technical Education for sponsoring the research under TAPTEC scheme (F.N ${ }^{\circ}$ : AICTE/TAPTEC/8020/RDII) and National University of Singapore for having supplied the composite material.

\section{References}

1. Soon LP, Gupta M. Synthesis and recylability of a magnesium based composite using an innovative disintegrated melt deposition technique. Journal of Material Science Technology. 2002; 18(5):92-98.

2. Xia XX, Sakaris P, McQueen HJ. Hot Deformation, Dynamic Recovery and Recrystallization Behavior of Aluminium 6061-SiC Composites. Journal of Materials Science and Technology. 1994; 16(8):487-496. 
3. Cerri E, Spigarelli S, Evangelista E, Cavaliere P. Hot deformation and processing maps of a particulate reinforced $6061 \mathrm{Al}+20 \% \mathrm{Al}_{2} \mathrm{O}_{3}$ composite. Journal of Material Science and Engineering. 2002; A324:157-161.

4. Sellars CM, Tegart WJMcG. Relation between strength and structure in hot deformation. Journal of Material Science and Engineering. 1966; 63:731-746

5. Venugopal S, Mannan SL, Prasad YVRK. Influence of state of stress on the processing map for hot working stainless steel type AISI 304L: Compression Vs Torsion. Journal of Material Science and Engineering. 1993; 160:63-69.

6. Cavaliere P, Cerri E, Leo P. Hot working and processing maps of a particulate reinforced $2618 / \mathrm{Al}_{2} \mathrm{O} / 20 \mathrm{p}$ metal matrix composite. Journal of Composites science and Technology. 2004; 64:1287-1291.

7. Semiatin SL, Jones JJ. Formability and workability of metals: plastic instability and flow localization. Metals Park, OH: ASM. 1984; 17(3)156-162.

8. Veh MS, Weng WP, Chuang TH. Plastic Flow Behavior during the Forging of $\mathrm{Al} / 10 \% \mathrm{Al}_{2} \mathrm{O}_{3}(\mathrm{P})$ Composite. Journal of Metals and Material Transactions A. 2000; 31:1310-1317.

9. Prasad YVRK, Sasidhara S, editor(s). Hot working guide: a compendium of processing maps, Warrendale. PA: ASM; 1999; p. 125-157.

10. Ganesan G, Raghukandan K, Karthikeyan R, Pai BC. Formability study on $\mathrm{Al} / \mathrm{SiC}$ composites. Journal of Materials Science Forum. 2003; 437:227230.

11. Radhakrishna bhat BV, Mahajan YR, Prasad YVRK. Effect of Volume Fraction of $\mathrm{SiC}_{\mathrm{p}}$ Reinforcement on the Processing Maps for $2124 \mathrm{Al}$ Matrix Composites. Journal of Metallurgical and Materials Transactions A. 2000; 31:629-639.

12. Poliak EI, Jonas JJ. Initiation of Dynamic Recrystallization in Constant Strain Rate hot Deformation. ISIJ International. 2003; 43:684-691.

13. Venugopal S, Mannan SL, Prasad YVRK. Optimization of Hot Workability in Stainless Steel Type AISI 304L using Processing Maps. Journal of Metallurgical and Materials Transactions A. 1992; 23:3093-3103.
14. Xia XX, Hugh J, Queen Mc, Sakaris P. Hot Deformation Mechanism in a $10 \% \mathrm{Al}_{2} \mathrm{O}_{3}$ Particle Reinforced $6061 \mathrm{Al}$ Matrix Composite. Journal of Scripta Metallurgica Materialia. 1995; 32:1185-1190.

15. RAJ R. Development of a processing map for use in warm-forming and hot-forming process. Journal of Metallurgical and Materials Transactions A. 1981; 12A:1089-1097.

16. Ganesan G, Raghukandan K, Karthikeyan R, Pai BC. Development of processing map for $6061 \mathrm{Al} / \mathrm{SiCp}$ composite material. Journal of Material Science and Engineering A. 2004; 369:230-235.

17. Cerri E, Spigarelli S, Evangelista E, Cavaliere P. An analysis of hot formability of the $6061+20 \% \mathrm{Al}_{2} \mathrm{O}_{3}$ composite by means of different stability criteria. Journal of Material Science and Engineering A. 2002; 327:144-154.

18. Hoffmanner AL. The use of workability test results to predict processing limits, metal forming; inter relation between theory and practice. New York: Plenum Press. 1961:349-391.

19. Srivatsan TS, Soboyego WO, Lederich RJ. Tensile Deformation and Fracture Behavior of a Ti-Alloy MMCs. Journal of Composites A. 1997; 28:365-376

20. Gourdet S, Montheillet F. An Experimental Study of the Recrystallization Mechanism during Hot Deformation of Aluminium. Journal of Material Science and Engineering A. 2000; 283:274-288.

21. Sivakesavam O, Prasad YVRK. Characteristics of Super plasticity Domain in the Processing Map for Hot Working of As-Cast Mg-11.5Li-1.5Al Alloy. Journal of Material Science and Engineering A. 2002; 323:270277.

22. Cho JR, Bae WB, Hwang WJ, Hartely P. A Study on Hot Deformation Behavior and Dynamic Recrystallization of Al-5\% Mg Alloy. Journal of Material Processing Technology. 2001; 118:356-361. 